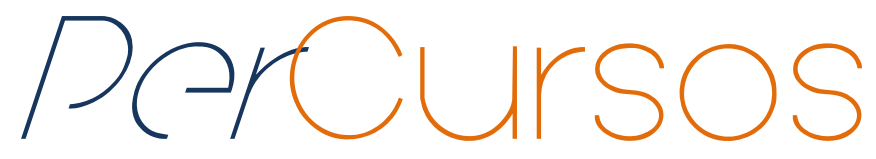

\title{
A construção da usina de Belo Monte e a urbanização dos indígenas xinguanos
}

\begin{abstract}
Resumo
O objetivo deste estudo foi analisar os problemas territoriais desencadeados ou aprofundados a partir da construção da Usina Hidrelétrica de Belo Monte, localizada na Região do Rio Xingu, na cidade de Altamira, Pará. A construção da hidrelétrica se deu sobre terras indígenas, de onde índios de aproximadamente 27 etnias foram expropriados e, por meio do Plano Emergencial do Governo Federal, foram relocalizados principalmente na Cidade de Altamira. Anteriormente às obras, essa cidade não tinha políticas públicas que atendessem de forma satisfatória sua população, de aproximadamente 13 mil habitantes. Com o processo de proletarização, direcionado para a construção da usina, e com a urbanização dos indígenas, num quantitativo de 100 mil habitantes, as políticas públicas deram sinal de total esgotamento. Nesse sentido, a mediação necessária a esses novos trabalhadores urbanos é a reivindicação por trabalho e políticas públicas, sem perder a disputa histórica pelo direito às terras indígenas, que é a luta pela existência indígena.
\end{abstract}

Palavras-chave: Terras Indígenas. Urbanização - Altamira (PA). Índios da América do Sul. Usina Hidrelétrica de Belo Monte. Etnocídio.

\section{Elizandra Garcia da Silva}

Doutorado em Educação na Universidade Federal do Amazonas; Professora do Instituto de Educação Física da Universidade Federal Fluminense. elizandragarcia@hotmail.com

\section{Arminda Rachel Botelho Mourão}

Doutorado em Educação na

Pontifícia Universidade Católica de São Paulo; Professora da

Universidade Federal do Amazonas; Docente do Programa de Pós-Graduação em Educação

da UFAM, PPGE/UFAM. arachel@uol.com.br

\section{Para citar este artigo:}

DA SILVA, Elizandra Garcia; MOURÃO, Arminda Rachel Botelho. A construção da usina de Belo Monte e a urbanização dos indígenas xinguanos. Revista PerCursos, Florianópolis, v. 19, n.40, p. 12 - 38, maio/ago. 2018.

\section{DOI: $10.5965 / 1984724619402018012$}

http://dx.doi.org/10.5965/1984724619402018012 


\title{
The construction of Belo Monte power plant and the urbanization of the xinguan indians
}

\begin{abstract}
The goal of this study was to analyze the territorial problems triggered or deepened by the construction of the Belo Monte Hydroelectric Power Plant, located in the Xingu River Region, in the city of Altamira, Pará. The construction of the power plant took place on indigenous lands, where Indians of approximately 27 ethnic groups were expropriated and, through the Emergency Plan of the Federal Government, were relocated mainly in Altamira. Previously to the works, this city did not have public policies that satisfactorily attended its population, of approximately 13 thousand inhabitants. With the process of proletarianization, directed to the construction of the plant, and with the urbanization of the indigenous people, a quantitative of 100 thousand inhabitants, the public policies gave signs of total exhaustion. In this sense, the necessary mediation for these new urban workers is the demand for work and public policies, without losing the historical dispute for the right to indigenous lands, which is the struggle for indigenous existence.
\end{abstract}

Keywords: Indigenous Lands. Urbanization - Altamira (PA). Indians of South America. Belo Monte Hydroelectric Plant. Ethnocide. 


\section{Introdução}

Estão em foco na atualidade os estudos dos movimentos sociais, principalmente daqueles que objetivam o direito à terra, como o Movimento Sem Terra, as comunidades remanescentes de quilombos e as comunidades indígenas. Tal interesse se dá especialmente pelos ataques históricos executados a esses movimentos pelos agentes do capital, isto é, latifundiários, empresários e governos.

Para as culturas indígenas, a questão da terra não é compreendida de forma urbanizada, parcializada, loteada, zoneada e com instituição de propriedade privada, como proposto pelo Plano Emergencial de Belo Monte, oferecido pelo governo federal por meio das empreiteiras responsáveis pelas obras. A terra, para os indígenas, se inscreve no sentido ontológico da pertença, lócus de produção e reprodução de sua existência. Assim como o ambiente, é entendida enquanto fornecedora de matériasprimas para a produção de valores de uso, e não para a produção de mercadorias (LUKÁCS, 1978).

Amparados nesse princípio, os indígenas de todo o mundo vêm resistindo historicamente a diversos ataques. No Brasil, na década de 1970, o governo militar foi ainda mais incisivo e estabeleceu políticas de desenvolvimento econômico para a Região Norte, alicerçadas na construção de grandes projetos que a colocassem na rota do crescimento econômico nacional, em especial por se constituir em uma Região com "enorme quantidade de recursos naturais passíveis de exploração, sobretudo mineral e hídrico", conforme Fonsêca e Gohn (2017, p. 68). Ampliando a análise dos autores, a leitura de Silva e Viana (2018) se deu em torno da afirmação de que a Região Amazônica possui um conjunto de forças produtivas a ser explorado, sendo a natureza integrante dessa totalidade. Logo, essa Região vem sendo alvo da exploração predatória do capital.

No bojo das políticas militares de crescimento econômico foram concebidos dois grandes projetos de geração de energia para a Região Norte: Tucuruí e Belo Monte. Tucuruí foi construída entre 1976 e 1984 e ocasionou graves impactos socioambientais, em especial por ter sido realizada no regime político de exceção, sob controle do exército e em período de legislação escassa sobre as questões ambientais, que prejudicam a vida 
da população da Região até a atualidade. Coube a nós evidenciar ainda o curso ascendente dos impactos sociais nas proximidades do Rio Tocantins, à baila na mídia atual pelos conflitos entre indígenas assentados e latifundiários bem como os processos indenizatórios não cumpridos pela Eletronorte com algumas etnias, dentre elas a Assurini (BRASIL, 2018).

Já a construção de Belo Monte foi suspensa motivada pela resistência indígena, ribeirinha e de movimentos sociais, dentre outros, que se ancoraram no risco que os estudos de impacto realizados representavam ao seu modo de produção e de vida, para se contrapor à realização da mesma.

Apesar de décadas de suspensão, os estudos de Fonsêca e Gohn (2017) registraram a retomada, a partir de 2007, de grandes projetos, sendo prioritária a Usina de Belo Monte. Contudo, essa proposição novamente ocorreu em articulação a um novo programa de desenvolvimento econômico nacional, o Programa de Aceleração do Crescimento (PAC). O projeto de Belo Monte refere-se à construção da Hidrelétrica no Rio Xingu, que atingiu de forma mais incisiva, Altamira, no estado do Pará.

Apreendemos da realidade, por meio de observação participante, registrada em diário de campo, duas modificações essenciais na relação que os indígenas xinguanos estabelecem com a terra. A observação foi realizada em dois momentos da pesquisa qualitativa exploratória: numa fase de contato e levantamento dos primeiros dados da realidade e numa fase analítica.

Na primeira fase estabelecemos o contato com o problema territorial ocasionado aos indígenas xinguanos pela construção da Usina. Podemos caracterizar essa observação como assistemática pois foi realizada a partir de um pré-projeto de pesquisa que objetivou identificar os conflitos existentes entre os sujeitos envolvidos com a obra de Belo Monte, quais sejam: os trabalhadores da construção civil, as empreiteiras, os indígenas e a população urbana de Altamira.

A esses primeiros dados da realidade dedicamos trato científico em forma de projeto de investigação, reelaborado e subsidiado por pesquisa bibliográfica da literatura da área e, documental abrangendo tanto os oficiais, expedidos pelo governo federal, 
quanto os elaborados pelo Ministério Público Federal, Painel de Especialistas, Comissão de Barragens, entidades sindicais e populares, e documentários de Organizações Não Governamentais/ONGs. Para, na segunda fase, tecer análise dos dados observados sistematicamente a partir da realidade, buscando nexos científicos subsidiários do entendimento da perda da relação ontológica dos indígenas com suas terras, assim como ocorreu com a maioria dos povos as margens do Rio Tocantins quando da obra de Tucuruí, e o processo de urbanização e proletarização aos quais foram submetidos pelo Plano Emergencial, peculiar às etnias xinguanas. Vale registrar que não pretendemos com este estudo esgotar as análises referentes à totalidade do problema e sim fornecer alguns subsídios para outros estudos, submetidos ao crivo da realidade histórica, conforme previsto pelo método dialético.

Partindo dessa realidade empírica, e com o intuito de tecer as devidas mediações científicas, compreendemos o fenômeno de defesa da terra e resistência à construção da hidrelétrica como defesa da própria existência do povo indígena. A partir dessa compreensão podemos afirmar que a relocalização territorial na cidade de Altamira e a venda de sua força de trabalho, em troca de um salário, para o pagamento de seu novo território, seus lotes urbanos com casa, cama, eletrodomésticos e outras mercadorias, que não eram valores de uso necessários quando desenvolviam sua relação ontológica com a terra e com o meio ambiente; são processos de urbanização e de proletarização. Ou seja, essas transformações colocaram em curso profundas modificações na produção e reprodução da vida dos povos indígenas do Xingu, como parte do processo de etnocídio desencadeado com a construção de Belo Monte.

Para tal análise, nos embasamos nas leituras marxianas com o intuito de que - ao traçar os nexos entre a realidade empírica em que vivemos e as leituras elaboradas dessa realidade conflitante - possamos elencar as contradições e confirmar nossa hipótese de que os conflitos envolvendo os povos indígenas e as construtoras de Belo Monte são mediações da própria luta de classes. Logo, compreendemos a luta do povo xinguano como luta dos trabalhadores e dos povos em resistência aos ataques da sociedade do capital em crise, buscando a retomada de seus níveis de acumulação. Nossa compreensão 
é de que essa luta se situa no marco classista, portanto persistirá até que se supere essa sociedade capitalista, pautada na expansão e na acumulação individualizada do capital.

\section{Os impactos socioambientais na construção das hidrelétricas brasileiras}

A construção das hidrelétricas brasileiras está estruturada no conjunto dos projetos e programas de desenvolvimento econômico do país. Assim, apesar de a utilização hidroenergética ter sido iniciada em fins dos anos 1800 e início dos 1900, é com o crescimento industrial das décadas de 1950 e 1960 que o governo priorizou a produção de energia elétrica, que veio se tornar fonte hegemônica em nível nacional (ROSA et al., 1995).

A necessidade de energia, advindas da produção industrial, atraiu investimentos do capital, nacional e internacional, que somente passaram a ser regulados com a criação da Eletrobrás, em 1962, a qual se coligavam as responsáveis regionais, importante para esses escritos a Eletronorte (MÜLLER, 1995).

Os estudos de Mendes (2005) evidenciaram o Banco Mundial como principal credor envolvido com as obras de produção energética, mas não se consolidou como financiador exclusivo, pois "Os vultuosos recursos financeiros necessários às obras passaram a ser captados no país e através de empréstimos internacionais, e repassados para a construção de grandes hidrelétricas nas diversas regiões [...]” (MENDES, 2005, p. 32).

Ao mesmo tempo em que a Eletrobrás e suas coligadas se ocupavam em angariar recursos financeiros para a projeção e execução das obras, alinhadas aos interesses do capital internacional e da burguesia industrial em formação, as construtoras se organizavam para a disputa das mesmas, não lhes interessando a realização de discussões com a sociedade ou o estabelecimento de estratégias que minimizassem os impactos à população e ao meio ambiente, atingidos pela estrutura física das hidrelétricas e pela extensão do alagamento de seus reservatórios (MENDES, 2005).

Os estudos de Rosa et al. (1995) indicaram a fonte hidráulica na produção energética como viável em se considerando as envolventes econômicas e os riscos 
ambientais. Porém, essa síntese reúne um emaranhado de contradições, dentre as essenciais a esse estudo, a melhoria da qualidade de vida da população e os impactos socioambientais, conforme identificou Souza (2000).

Apesar de o curso histórico evidenciar que a produção de energia elétrica foi impulsionada pelo processo industrial, Souza (2000) referendou que a mesma deveria viabilizar melhor qualidade de vida à maioria da população brasileira. E, ao objetivar a qualidade de vida, em totalidade, indicou a pertinência dos estudos dos impactos socioambientais, desde a fase inicial dos projetos, persistindo durante a construção e seguindo durante a produção energética.

O temário socioambiental somente passou a protagonizar destaque internacional e nacional na medida em que alguns recursos naturais foram dando sinais de enfraquecimento ou esgotamento enquanto força produtiva de sustentação do capital, destarte a crise do petróleo, na década de 1970. Essa crise desencadeou uma série de debates internacionais sobre Meio Ambiente, promovidos pela Organização das Nações Unidas/ONU e os países participantes, que passaram a demandar legislação referente ao tema (SILVA; VIANA, 2018).

No Brasil, as políticas internacionais emanadas desses espaços coordenados pela ONU estão impressas na Política Nacional do Meio Ambiente, na Constituição Federal, nas deliberações da Conferência Eco 92, signatárias legais e propulsoras dos Estudos de Impacto Ambiental/EIA, da Licença Ambiental, da aceleração das demarcações das Terras Indígenas/TI e da atenção para projetos de preservação ambiental, dentre outras (SILVA; VIANA, 2018).

Porém os estudos, projetos e construção das maiores hidrelétricas brasileiras foram realizados na década de 1970, anterior ou concomitante às novas demandas socioambientais, causando danos irreversíveis, dentre elas Belo Monte, Tucuruí, Itaipu e Sobradinho (FONSÊCA, 2018). Aproximam ainda essas usinas características como tamanho, investimentos, prioridade de abastecimento ao setor econômico, tanto em território nacional quanto internacional, e danos socioambientais amplos e profundos. 
No referente aos impactos ambientais, os estudos da Comissão Mundial de Barragens (1999) identificaram que a construção e funcionamento das hidrelétricas provocam modificações no clima, na geomorfologia, na hidrografia, na vegetação, na geologia, nos solos, na qualidade da água, na fauna e na ictiofauna, em especial devido à construção das barragens que prejudicam a vida e reprodução dos peixes e outras vidas aquáticas pois passaram a impedir o trânsito durante o período da piracema. Souza (2000) detalhou que a mudança da correnteza do rio facilita o acúmulo de depósitos no fundo, resultando em reações químicas nocivas à vida humana e ainda diminuindo a temperatura em relação à superfície, o que também afeta a vida e reprodução dos animais.

Os estudos comparados de Pinto (2012) identificaram similidades entre Tucuruí e Belo Monte por serem as maiores obras públicas da Amazônia, danosas ao meio ambiente sem precedentes na Região e pelo quantitativo de desapropriação indígena e ribeirinha. A partir dos estudos desse autor (2012) compreendemos a retirada dos sujeitos das margens do Rio Tocantins para as obras de Tucuruí como expropriação, realizada de forma peculiar; houve expropriados que foram retirados de suas terras sem nenhum tipo de compensação, enquanto aguardam justiça, se auto-organizam em casas de parentes, em ilhas que se formaram nas áreas alagadas pelo reservatório, ou foram para a área urbana de Tucuruí; e outros foram indenizados, com terras de valores inferiores as que possuíam e em locais de conflitos com latifundiários. Dentre esses, alguns resistem, outros foram mortos, ou há ainda os que abandonaram ou venderam suas terras e migraram em busca da retomada de seu antigo modo de vida.

No mesmo escopo do pensamento de Souza (2000) os estudos de Müller (1995, p. 45) haviam denunciado impactos sociais profundos, “[...] sociedades que viram suas bases de sustentação econômica e seus valores socioculturais repentinamente solapados" vivenciando "[...] retrocesso insustentável”. Os autores (1995) discorreram acerca das transformações ocorridas na vida da população atingida, em sua maioria, removida das áreas atingidas sem nenhuma, ou com medidas compensatórias aquém do necessário, como estudado por Mendes (2005, p. 45); 
[...] com a implementação das usinas hidrelétricas, milhares de famílias perderam suas terras e residências. Muitas famílias deixaram de ser reassentadas, e aquelas que receberam indenizações, muitas vezes, não conseguiram comprar novas terras, em virtude do valor irrisório recebido.

No referente à Belo Monte, motivados também pelos estudos Ambientais realizados na década de 1970, houve a resistência indígena, e de movimentos sociais que se solidarizaram aos povos xinguanos, e juntos derrotaram por alguns anos o projeto de construção da hidrelétrica, mas isso representou uma vitória parcial, pois com a crise energética de 2001-2002, os governos que seguiram retomaram essa obra como prioritária, e

\begin{abstract}
Abstraia-se toda a questão ecológica e etnológica. Admita-se, em princípio, que os 'barrageiros' têm razão: o represamento do Xingu não irá causar grandes danos ambientais (todos passíveis de prevenção ou reparação) e que o prejuízo às comunidades indígenas atingidas será mínimo, assim como à população de Altamira, (PINTO, 2012, p. 780)
\end{abstract}

Priorizada a execução do projeto de Belo Monte, bem como os acordos com empreiteiras envolvidas nessa ou em outras obras públicas nacionais, o governo federal contratou a Camargo Correa, a Andrade Gutierrez e a Odebrecht para a elaboração do Relatório de Impacto Ambiental/RIMA em atendimento e realizando diversas adaptações às normativas socioambientais vigentes. Esse Relatório foi questionado pela população, indígenas e Ministério Público Federal, sob a acusação de haver minimizado os resultados negativos dos impactos, porém a obra teve prosseguimento devido à liberação judicial para a construção, sem embargos até decisão em instância final, permitindo a conclusão e inauguração em 2016 (PINTO, 2012). 


\section{Os indígenas xinguanos e a construção da usina de Belo Monte}

Neste tópico, ocupamo-nos em situar os conflitos existentes entre os povos indígenas da Região do Rio Xingu e a construtora da Usina Hidrelétrica de Belo Monte, compreendidos por nós como uma mediação dos conflitos classistas próprios da sociedade do capital, em curso historicamente.

Os conflitos entre os povos indígenas e os interesses do capital nessa Região não são recentes, mas históricos. Nessa esteira, atentamos para a compreensão de que os interesses desses dois polos são conflitantes e irreconciliáveis, pois, de um lado, estão o capital e o governo em defesa da finalização da obra, por completo; do outro, os indígenas, defensores de sua terra e de sua existência.

No tangente à construção da Usina Hidrelétrica no Rio Xingu, esses conflitos datam da década de 1970, como marco dos primeiros estudos realizados acerca da viabilidade da obra. Vale registrar que, naquela década, a construção das usinas hidrelétricas na Região Norte do país compôs o programa nacional de desenvolvimento econômico para a Região, ou seja, a Usina de Belo Monte constituía parte de uma política militar em nível nacional, e não apenas focalizada em Altamira (KOHLHEPP, 2002).

A partir desse período e à medida que o capital - por meio das construtoras, do governo e seus agentes - foi ganhando forças para a efetividade dessas obras, os indígenas, a população regional e os trabalhadores da própria construção também se organizaram e resistiram aos ataques. Esses conflitos são constantes e não apenas no sentido de luta pela defesa da terra e da própria existência desses indígenas, mas também se caracterizam como conflitos culturais, pois a expropriação dessas terras e a modificação de seu modo de produção alteram qualitativamente sua cultura, seus costumes e seus modos de vida (THOMPSON, 1998).

O avanço dos ataques do capital, por intermédio dos projetos de desenvolvimento econômico, tem como resposta histórica a resistência indígena, que principia uma organização sistemática a partir da década de 1970, em nível nacional, e em 1989, 
materializado a particularidade da construção de Belo Monte com o I Encontro dos Povos Indígenas do Xingu, referência na luta indígena mundial (FONSÊCA, 2018).

Após alguns anos inativa, o que havia representado uma vitória momentânea dos povos indígenas, a construção da hidrelétrica foi retomada. A partir de 2007, o projeto de Belo Monte foi inserido nas políticas econômicas nacionais do PAC, que aglutinou a construção dos grandes projetos para a Região, sendo essa usina de ordem prioritária em nível nacional (FONSÊCA; GOHN, 2017).

Mesmo após a realização dos estudos e a conclusão de que Belo Monte tem produção de energia cerca de 10\% abaixo das principais hidrelétricas nacionais, e possuir alto custo, houve a insistência do governo federal na construção, embasado na assertiva de se igualar às médias das demais geradoras nacionais. Essa insistência evidenciou o posicionamento do governo ao lado das construtoras, mais bem compreendido na medida em que as investigações foram identificando irregularidades na obra, que envolveram empresários das construtoras e partidários do governo.

Por outro lado, para os indígenas, a insistência do governo em superar os estudos realizados e buscar igualar a produção de energia de outras geradoras é preocupante, pois, com o projeto inicial já inaugurado, nem todas as etnias foram desterritorializadas, e com a conclusão há etnias que ficarão completamente embaixo d'água, como é o caso da Juruna, que na atualidade sobrevive com seus costumes tradicionais e recursos naturais, preservados em suas terras. A relação do povo Juruna com o Rio Xingu é tão intensa que “o rio determina o calendário das atividades e a trajetória de vida dessas famílias", segundo Scachetti e outros (2013, p. 1).

Em acordo ao entendimento da relação estabelecida entre os povos indígenas e a natureza, o documentário Belo Monte: anúncio de uma guerra apresentou entrevistas de várias lideranças das 26 etnias indígenas da Região do Rio Xingu. Tais líderes demarcaram que o conflito se pauta não pela propriedade privada da terra, e sim porque a terra é a própria vida desses indígenas, sendo dela retirada sua própria existência, mesma relação que esse povo mantém com o Rio Xingu, onde pescam, tomam banho, retiram água, brincam, se transportam (BELO..., 2012). 
O projeto de Belo Monte não interfere somente no Rio Xingu. O represamento estende-se para outros rios, sub-bacias, igarapés e terras indígenas, como é o caso da Terra Indígena da Trincheira Bacajá, onde todas as comunidades que a compõem vivem exclusivamente das atividades de pesca, caça e extração de castanha, açaí e outros. Já o povo Arara, que também será atingido, tem suas atividades de produção e reprodução enquanto povo marcadas pela mescla da caça com a agricultura, e se utiliza do rio para transporte, banho, brincadeiras e outros. Os Parakanã são especializados em caça de animais terrestres e, antes do contato com os sujeitos não indígenas, não tinham a pesca como atividade central, diferente da atualidade. Esse povo será quase completamente realocado com a construção da usina (BELO..., 2012).

Esses são alguns exemplos de que a desumanização dos povos indígenas está presente em todo o processo de construção e funcionamento da Usina Hidrelétrica de Belo Monte, apesar das afirmações contrárias por parte do governo federal e do consórcio de construtoras. Justifica-se que foi um processo de construção democrática, em especial junto ao Instituto Brasileiro do Meio Ambiente e dos Recursos Naturais Renováveis (Ibama), órgão que durante o processo de construção da usina, escamoteou os estudos de impacto socioambientais, se posicionou a serviço do governo e legou pareceres favoráveis a tal construção.

Assim, com a retomada do projeto da Usina Hidrelétrica de Belo Monte como constituinte do PAC do governo federal, apesar da resistência indígena e da solidariedade dos movimentos sociais e de trabalhadores que se somaram à luta, os indígenas do Xingu e o movimento de resistência indígena brasileiro tiveram uma derrota histórica: a hidrelétrica foi construída, os indígenas xinguanos perderam suas terras e foram alocados em outros territórios, em especial na cidade de Altamira. 


\section{Os indígenas do xingu e a construção da usina hidrelétrica de Belo Monte:}

Rememorando as questões introdutórias, pensamos ser necessário prestar os nexos científicos para a compreensão dos conflitos da Região do Rio Xingu, bem como da luta e resistência do povo xinguano. Nesse sentido, consideramos importante situar nosso entendimento de que os conflitos do capital com os trabalhadores e com os povos não se dão de forma isolada na Região Amazônica, por ser o conflito próprio do seio dessa sociedade. Não são conflitos recentes, mas acompanham o desenvolvimento histórico e social das nações, a depender de seus níveis de desenvolvimento das forças produtivas, como nos ajuda a compreender Alcimar Oliveira (2011, s/p), ao se reportar à cidade de Manaus, no estado do Amazonas:

[...] asseguro-lhes que poderia falar da barbárie como algo distante, e num texto asséptico. Mas estou em Manaus, no Amazonas e no Brasil, onde o sociometabolismo do capital amesquinha o Estado e este faz definhar o pouco que resta de sociedade civil [...].

O modo de produção capitalista - enquanto sistema social de metabolismo do capital, ao qual o Estado é subserviente - vem passando por profundas mudanças, em especial expressadas nas esferas política e econômica, desde as três últimas décadas do século XX, as quais entendemos interferem diretamente no conflito do Xingu.

Essas transformações econômicas são o resultado de uma crise no padrão de acumulação taylorista-fordista, aflorando um padrão de acumulação flexível, com substancial impacto sobre o trabalho, os trabalhadores e o povo (ANTUNES, 2001). 0 taylorismo-fordismo marcou profundamente a organização do trabalho e dos trabalhadores durante longo período do século passado. Porém, a partir da década de 1970, esse padrão de acumulação perdeu forças e entrou em crise, carecendo do aprofundamento das formas de exploração das forças produtivas, configuradas nos projetos de desenvolvimento econômico para a Região Norte do Brasil, por exemplo. 
Além disso, no âmbito estatal, desde o início da aplicação da cartilha neoliberal no Brasil, tardiamente em relação aos países de capitalismo desenvolvido, datado da década de 1990, passou a haver dois aspectos intervencionistas fundamentais: Estado mínimo para as questões públicas, como educação, saúde, segurança, e Estado máximo para as questões do capital privado - ou seja, foi aprofundada e ampliada a exploração das forças produtivas. Entre os resultados está o empobrecimento da população, ao mesmo tempo em que as políticas públicas voltadas aos serviços públicos foram sendo precarizadas, dificultando ainda mais a vida do trabalhador (ANTUNES, 2001).

Como esclarece Oliveira (2011, s/p), há mediações da sociedade do capital à Região Amazônica, e esse sistema sociometabólico "tende sempre a aprimorar seu modus operandi sobre os povos e terras da Amazônia, mas jamais alterar seu ratio essendi, intrinsecamente etnocida e ecocida" evidente com a construção da Usina Hidrelétrica de Belo Monte (grifos do autor).

Esse contexto histórico-social do capitalismo obedeceu a algumas considerações marxianas da leitura de Antunes e Silva (2010) acerca do desenvolvimento das forças produtivas e do capital, com particularidades, apesar de global e mundializado, à Região Amazônica. A cidade de Altamira, por exemplo, antes da obra, possuía pouco mais de 13 mil habitantes, a maioria de indígenas, caboclos e ribeirinhos. Durante e após a construção da hidrelétrica, o município teve sua composição alterada, recebendo majoritariamente trabalhadores da construção civil, profissionais liberais e funcionários públicos, evidenciados nos quantitativos populacionais em mais de 100 mil habitantes na atualidade (IBGE, 2018).

Nesse sentido, Antunes e Silva (2010, p. 10) já alertavam que, "por trás de aparente hegemonia e universalidade de situações", há diferenças entre os países "ricos e pobres, centrais e subordinados, e também no interior dos mesmos"; e, dentro dessas particularidades, entre os diversos setores da economia. Eles acrescentaram as particularidades de gênero, diversidade de etnias, geracional e etária como necessárias à compreensão da situação da classe trabalhadora e dos povos. Apesar de tardiamente, se comparados aos projetos de desenvolvimento econômicos da Região Sudeste do país, as grandes obras também foram destinadas à Região Amazônica, sendo expressivas a 
Rodovia Transamazônica, o projeto de exploração mineral de Carajás, e as usinas de Balbina e Tucuruí, compreendidas por Oliveira (2011, s/p) como componentes do rol de barbárie do capital.

Nesse sentido, são evidentes os interesses do capital e do governo na construção da Usina Hidrelétrica do Xingu, em detrimento dos interesses dos povos indígenas, caboclos, ribeirinhos, extrativistas e demais habitantes da região. Além das irregularidades financeiras envolvendo a construtora e o governo, que estão sendo investigados, o documentário Belo Monte: anúncio de uma guerra denuncia como principais interessados nessa construção as construtoras, as indústrias exploradoras de recursos naturais, em especial de minério de ferro, química, cimento, papel e celulose (BELO..., 2012).

Constituindo o agrupamento do capital internacional interessado em Belo Monte, ocultado pelo governo federal, estão a China, a França, os Estados Unidos, a Alemanha e a Áustria, por meio das empresas Tractebel, GDF-Suez e Alston. Por outro lado, atores e sujeitos locais, que impõem a resistência ao governo e ao capital, são compostos por indígenas, ribeirinhos, castanheiros, seringueiros, pequenos agricultores, pequenos posseiros e pequena burguesia mercantil (OLIVEIRA, 1994).

As consequências desse conflito estão marcadas pelo genocídio e etnocídio, inclusive quanto aos saberes tradicionais desses povos, e pela degradação ambiental, expostas por Alcimar de Oliveira (2011, s/p) como exemplos de barbárie do capital à Região Amazônica:

Diante de tantos erros e equívocos, com perversos e irreversíveis danos ao mundo da Amazônia, sempre legitimados pela arrogante e surda certeza da tecnociência - e bastaria aqui mencionar, pela sua monstruosidade irracional, a Hidrelétrica de Belo Monte no rio Xingu [...].

Como nos alertam as imagens e falas dos especialistas, no documentário dirigido por D’Elia (BELO..., 2012), o Rio Xingu somente será capaz de produzir energia durante 
cinco meses por ano, no máximo, devido ao período de vazante marcado pela ausência de chuvas, típico da Região Norte do país. Esse é apontado como um dos motivos que afastou as grandes construtoras da função de proprietárias de ações da hidrelétrica, para meras prestadoras de serviço, transferindo-se a responsabilidade para o governo federal. O questionamento de Oliveira (1994, p. 89), muito pertinente para a década de 1990, permanece relevante ainda hoje:

O problema concreto é se o Estado brasileiro quer renunciar à exploração das riquezas da Amazônia, que lhes fornece os meios de uma nova inserção na expansão capitalista contemporânea. Em caso positivo, se tem os meios para tanto, terá que controlar a bestial exploração humana e a colossal depredação ambiental a que sua estratégia abriu as portas.

Assim como não houve dúvidas acerca dessa intervenção governamental por parte de Fernando Henrique Cardoso, na década de 1990, os presidentes Lula e Dilma não hesitaram em colocar o Estado brasileiro a serviço do capital, como mediador da persistência na construção da Usina Hidrelétrica de Belo Monte, que movimentou o capital da construção civil e explorou forças produtivas ainda em certo estado bruto, como a força de trabalho indígena, direcionada à produção de artesanato como mercadoria, no sentido mercantil e empreendedor, como previsto pelo Plano Emergencial.

A intervenção do Estado brasileiro foi se efetivando por meio da Eletrobrás e da Eletronorte, e ainda por meio do Ibama, da Funai, de policiais militares e civis, deputados, senadores, enfim, todos os entes envolvidos nas aprovações dos projetos de lei e na defesa da continuidade das obras dessa hidrelétrica. Não controlando a exploração humana e não defendendo o meio ambiente, no sentido apontado por Oliveira (1994, p. 89), o Estado brasileiro "abriu as portas" da Região do Rio Xingu para a expansão econômica e a morte do povo indígena e do povo de Altamira, uma vez que as políticas públicas sociais dessa cidade têm demonstrado esgotamento diante da expansão urbana alçada pela construção da hidrelétrica. 
O Estado brasileiro está intervindo no sentido que já sinalizou Oliveira (1994, p. 08): “o monopólio da violência pelo Estado acoberta toda espécie de violência privada, esta é a forma concreta da proteção de fronteiras e do bloqueio à vulnerabilidade". Ou seja, o Estado está assumindo, a partir de todos os seus agentes, inclusive as Forças Armadas, o projeto da construção da usina, escondendo o capital internacional, que é o real interessado em tal construção.

O Plano Emergencial, firmado entre o Estado, por meio da FUNAI, e a Norte Energia, expediu em 2011 o Boletim Informativo número 2, impulsionado no pressuposto de que, como foi assinado pela FUNAl os indígenas margeados do Rio Xingu automaticamente se tornam seus signatários e esclarecidos dos objetivos de:

Fortalecimento da atuação da Funai na região de Altamira com apoio de infra-estrutura, equipamentos e pessoal qualificado para executar as atividades emergenciais de promoção ao etnodesenvolvimento; Fornecimento de subsídios para a criação do Comitê Gestor que irá acompanhar e fiscalizar a execução dos programas e ações que serão detalhados no PBA; Fortalecimento das relações das comunidades com as Terras Indígenas, afastando-se a necessidade de ir a cidade; Criação de condições para que os indígenas possam ir até Altamira, quando necessário, sem prejuízo da sua identidade, da sua posição social ou do livre exercício dos seus direitos; Fortalecimento das associações indígenas [...] (PROGRAMA, 2018, p. 04)

O entendimento de etnodesenvolvimento do Plano foi se estruturando no sentido do abandono cada vez maior do modo de produção extrativista como a caça, a pesca e a coleta de sementes e frutos e das roças que passaram a ser desnecessários com o recebimento dos aproximadamente $\mathrm{R} \$ 10.000,00$ (dez mil reais) previstos pelo Plano, para cada comunidade.

O abandono do modo de produção e a destinação de aproximadamente $\mathrm{R} \$$ 30.000,00 (trinta mil reais) para o que o Plano intitulou de "segurança alimentar", estimando a complementação e melhoria alimentar das comunidades, mas que segundo os estudos de Fonsêca (2018) houve introdução descontrolada de alimentos 
industrializados, o que nos leva a afirmar a ocorrência de uma ameaça alimentar, resultante em $1 / 4$ (um quarto) das crianças indígenas desnutridas e no aumento num quantitativo de 2.000 \% (dois mil) nos atendimentos em saúde na cidade de Altamira após o início das medidas do Plano Emergencial (FONSÊCA, 2018).

Apesar de o Plano ter previsto a fiscalização e proteção das Terras Indígenas, houve a expropriação para a própria obra e a relocalização desses povos em outros locais o que o autor chama de violência, uma vez que expulsaram os povos de suas terras, e com isso modificaram a produção da existência desses povos, conforme relatado por Oliveira (2011, s/p):

\begin{abstract}
Na Amazônia, cujas tradicionais formas de produção da existência social sempre as caracterizam por um regime de simbiose entre natureza e cultura, é sob a intervenção do capital que vamos ver o progressivo e largo desequilíbrio dessa relação, presidida a partir de então pelo domínio programado do parasitismo sobre a simbiose. Conceitos vindos do mundo da biologia, parasitismo e simbiose sofrem a partir da consolidação e expansão do modo de produção capitalista uma inflexão até então desconhecida pela história humana.
\end{abstract}

No sentido do exposto pelo autor, observamos que os Planos Emergenciais delineados para localização dos indígenas em outras áreas rurais, mas principalmente os de localização na área urbana de Altamira, ocasionam um rompimento com os moldes tradicionais da produção e reprodução da existência desses povos, com afastamento entre natureza e cultura e incorporação da urbanidade na medida em que foram se utilizando dos aproximados $\mathrm{R} \$ \mathbf{2 0 0 . 0 0 0 , 0 0}$ (duzentos mil reais) a serem empregados em infraestrutura para adquirir mercadorias antes sem valor de uso, como carros, motos, camas, geladeiras, televisores, dentre outros (FONSÊCA, 2018; PROGRAMA, 2018).

A proposição desses Planos desconsiderou o extrativismo e a relação com a natureza como a própria existência dos povos indígenas, assim como delegou que seus saberes tradicionais fossem colocados não mais para a produção dos produtos com 
valores de uso necessários a suas vidas, e sim como fomento à produção de mercadorias, ao propor cursos de empreendedorismo para a produção de artesanato, dentre outros.

Essa violência do Estado é concreta no ataque a esses saberes tradicionais da cultura indígena, bem como a expropriação desses conhecimentos, cujo condicionamento, aliado ao trabalho desses povos a serviço do capital, está definido, na estimativa do governo, dos seguintes benefícios para a população indígena:

\begin{abstract}
Capacitação para atividades econômicas em bases sustentáveis (artesanato, extrativismo vegetal, apicultura, plantio de cacau, de frutíferas nativas e de ervas medicinais, criação de animais e etc.) e para a comercialização da produção. Fornecimento de infraestrutura para escoamento da produção e de equipamentos para facilitar as atividades produtivas. Apoio ao serviço de educação formal das populações indígenas (capacitação de professores indígenas, promoção de trocas culturais com outras terras indígenas e readequação da infraestrutura da educação. Melhoria das habitações [...]. desenvolvimento de ações de segurança territorial das terras indígenas [...]. capacitação de agentes ambientais indígenas. Incentivo à capacitação profissional e desenvolvimento de atividades produtivas nos onze municípios da área de influência indireta do projeto. Incentivo a qualificação profissional. Avaliação das oportunidades de novos negócios, aproveitando as potencialidades locais. Contribuição para a organização dos produtores em associações e para a formação de empreendedores. (SCACHETTI et al., 2013, on line)
\end{abstract}

O primeiro benefício prometido pelo governo submete os indígenas dessa região a trasladar o trabalho de artesanato, extrativismo vegetal (em especial açaí e castanhas), apicultura, pequenas agriculturas e criação de animais, que já desempenham como valores de uso, para valores de troca, resultantes em produtos a serem comercializados. O comércio também é subsidiado pelo governo, que justificou o ataque à cultura indígena com o discurso da sustentabilidade, ou seja, retirar da natureza de maneira que não se esgote a fonte de exploração do capital, mesmo que o novo status desses produtos seja de mercadorias a serem colocadas no mercado para a venda. 
Ainda na esteira do desenvolvimento direto do capital estão as últimas promessas, que abordam questões desconhecidas da vida indígena, pautadas pelos conhecimentos populares e de transmissão oral, como a profissionalização, a capacitação profissional, a avaliação e o fomento do mercado, numa tentativa clara de maximizar as forças produtivas locais e colocá-las a serviço da exploração do capital.

Acerca da educação formal dos povos indígenas, acreditamos ser importante resgatar que, dentre as bandeiras dos movimentos indígenas organizados, está a educação bilíngue, ou educação intercultural/multicultural indígena, não valorizada nas promessas do governo, o que distancia ainda mais o índio de sua existência tradicional e de sua cultura (SILVA, 2000).

As habitações indígenas são peculiares e integram seu modo de vida. Apesar de esse aspecto soar como menos importante, a oferta de eletrodomésticos, eletrônicos, móveis e utensílios foi promovendo transformações culturais aceleradas na vida dos indígenas, além da estimulação à utilização de valores de uso que não faziam parte de sua cultura, como a cama, o chuveiro elétrico, a geladeira, dentre outros.

A mencionada capacitação de agentes de segurança territorial estimula a relação de propriedade privada da terra, qualitativamente distinta da relação ontológica que mantinham com as terras indígenas, de onde retiram sua existência e a partir das quais respeitavam a existência das demais etnias ao seu redor.

Estudos realizados na região, anteriormente à construção da usina, já afirmaram suas consequências para o meio ambiente. Nesse sentido, entendemos que a sugestão de agentes ambientais procura minimizar esses problemas, direcionando aos indígenas a responsabilidade gerada pelo governo e construtora, ou seja, redirecionando o foco dos problemas ambientais cometidos pela obra.

Vale se lembrar dos estudos de Oliveira (2011, s/p), para quem não é possível dialogar sobre o quesito tempo da sociedade do capital, mediado à vida indígena-cabocla: "Nesse mundo, o tempo é espaço do usufruto, o que é impensável no ritmo e na escala da produção capitalista”. Ou seja, no que se refere à relação estabelecida com o tempo, há profundas transformações na vida indígena com a inauguração de Belo Monte. Por 
exemplo, após a inauguração de Belo Monte não se pode mais conceber que a cheia e a vazante dos rios determinem a vida das diferentes etnias, como ocorria antes das obras.

O fenômeno de acirramento na proletarização da força de trabalho, antes menos explorada, não é recente, nem mesmo na Região Norte. No escopo dessa conjuntura, de tentativa de crescimento nacional integrado, as transformações nas vidas dos trabalhadores e dos povos, nas capitais e em especial nas cidades do interior dos estados amazônicos, foi realizada com ênfase na década de 1970, com o projeto de desenvolvimento militar, o processo migratório de trabalhadores até então produtores e reprodutores sob o extrativismo ou a agricultura de subsistência, sem experiência industrial e comerciária, para a Zona Franca de Manaus, como exemplificou Mourão (2006).

Esse fenômeno de proletarização e urbanização dos trabalhadores amazônicos foi recorrente com a construção de Belo Monte, com os variados sujeitos sociais: há indígenas, caboclos, ribeirinhos e trabalhadores da construção civil de Altamira, de toda a região e do Brasil, que se deslocaram buscando emprego na construção dessa usina hidrelétrica. Esses trabalhadores, em sua maioria sem experiência na construção civil, instalaram-se de forma precária na cidade de Altamira. Em pouco tempo, foram acometidos por doenças, alcoolismo, uso de drogas, problemas de estruturação familiar; e as políticas municipais, que já eram insuficientes para a população de pouco mais de 10 mil habitantes, não suportaram o aumento da demanda, ocasionando questões sociais irreversíveis (BELO..., 2012).

Inserindo a compreensão da construção da Hidrelétrica de Belo Monte aos projetos mais amplos do capital nacional e internacional, foi possível compreender que esse projeto colocou em curso o aprofundamento da exploração das forças produtivas na Região Norte do Brasil, em especial na cidade de Altamira. A expropriação da terra indígena e a construção da usina atenderam à especulação imobiliária, à construção civil, aos envolvidos nos desvios de verbas que estão sendo investigados, às empreiteiras, às empresas internacionais que possuem interesses na energia da região, dentre outros. 
O traslado dos indígenas para a cidade de Altamira e o trabalho no Plano Emergencial colocaram à disposição do mercado muita força de trabalho de baixo custo, especializada nas atividades de conhecimentos tradicionais, necessários às empresas internacionais que exploram a Amazônia, como a Natura e a Coca-Cola (SILVA, 2015). Essa alteração no modo de vida do indígena está transformando sua cultura, assim como algumas etnias foram expropriadas por completo, e em alguns anos serão culturalmente extintas.

No que tange às questões urbanas, tanto os indígenas quanto o processo de proletarização dos trabalhadores, que se destinaram a Altamira à procura de emprego na construção da hidrelétrica, aprofundaram a precarização do oferecimento das políticas públicas, colocando a população em condições desumanas de vida.

\section{Considerações Finais}

Em síntese, a construção da Usina Hidrelétrica de Belo Monte ocasionou, assim como as antecedentes brasileiras, impactos sociomabientais irreparáveis. A inauguração da mesma, em 2016 não estancou os prejuízos ao meio ambiente pois o processo de produção energética seguirá interferindo nas modificações do clima, da geomorfologia, da hidrografia, na vegetação, na geologia, dos solos, da qualidade da água, da fauna e da ictiofauna, dentre outras.

E, acerca dos impactos sociais, como afirmamos desde o início, situados no bojo da luta do capital com os povos indígenas como mediação da própria luta de classes. Consideramos ainda que o processo de proletarização dos trabalhadores da região - em sua maioria caboclos e ribeirinhos, anteriormente trabalhadores em atividades extrativistas de subsistência e deslocados para a construção da usina - não será reversível. Assim como podemos considerar, a partir de alguns estudos exploratórios na área da saúde, registrados no decorrer deste artigo, que a urbanização dos indígenas vem sendo conflituosa. Logo, são necessárias políticas sociais públicas emergenciais e nas 
proporções do quantitativo crescimento estimulado pela construção da Usina Hidrelétrica de Belo Monte.

A construção da Hidrelétrica de Belo Monte representou uma derrota histórica para a população da Região, quanto à alteração de seu modo de vida, e em especial aos povos indígenas, pois não perderam apenas suas terras, mas também a sua existência, a partir do princípio de que a relação estabelecida com a terra se constitui como uma relação ontológica, ou seja, da própria vida.

No bojo da luta de classes, nossa tarefa, enquanto professores/trabalhadores comprometidos com as lutas sociais, inscreve-se além da busca pelas necessidades mais imediatas de melhores condições de trabalho e de vida, mas também em entender esse conflito como um desafio de nosso cotidiano enquanto sujeitos amazônicos, desde a educação à organização social.

As leituras gramscianas de Edmundo Dias (2006) afirmaram que, para combater as noções deterministas imputadas pelo capital, a parte da massa que tem características de direção deve auxiliar os demais trabalhadores e o povo a superar o pensamento capitalista, que não é o da sua classe, e construir o seu próprio, construir a hegemonia da classe subalterna. O autor continua a descrever o desafio de classe:

Trabalhar incessantemente para elevar intelectualmente estratos populares cada vez mais vastos, [...], para dar personalidade ao amorfo elemento da massa, o que significa trabalhar para suscitar elites de intelectuais de um tipo novo que surjam diretamente da massa, permanecendo [...] em contato com ela [...]. Esta [...] necessidade, se satisfeita, é a que realmente modifica o "panorama ideológico" de uma época. (DIAS, 2006, p. 74)

Nesse sentido, enquanto sujeitos amazônicos, e com o intuito de continuarmos nos formando enquanto intelectuais orgânicos da classe trabalhadora, conceituada do pensamento gramsciano, é necessário fortalecer, por meio das entidades sindicais e estudantis, o apoio à luta dos povos indígenas. Este artigo nos possibilitou tecer alguns 
nexos de compreensão entre a realidade concreta dos povos do Xingu e as análises científicas. Irmos contra a construção da Usina Hidrelétrica de Belo Monte é a única forma de salvar os povos indígenas daquela região e evitar a guerra anunciada pelo documentário de D’Elia (BELO..., 2012). Como afirmamos, a guerra só não se aprofundou no sentido da barbárie, tão presente na tese de Oliveira (2011), devido à resistência dos movimentos que se organizaram contra a construção e ainda à greve dos trabalhadores da construção por motivos de super-exploração, dentre outros. Contudo, com a inauguração da hidrelétrica, em 2016, a extinção de diversos povos e suas culturas, costumes, conhecimentos populares e saberes passa a ser uma realidade cada vez mais presente.

Finalmente, para retomar a conotação dialética deste estudo, sinalizamos que a única forma de o ser humano vencer esse desafio amazônico é reconhecer o processo de conflitos entre as classes sociais e transformar a sociedade capitalista, superando a organização sociometabólica do capital e estabelecendo relações de associação livre para a produção de suas necessidades de uso, eminentemente humanas. Desse modo, suas objetividades e subjetividades voltarão a expressar as características do ser omnilateral, construção histórica necessária para a continuidade da existência dos trabalhadores, dos estudantes e dos povos indígenas. 


\section{Referências}

ANTUNES, Ricardo. Os sentidos do trabalho: ensaios sobre a afirmação e a negação do trabalho. São Paulo: Boitempo, 2001.

ANTUNES, Ricardo; SILVA, Maria Moraes (Orgs.). 0 avesso do trabalho. 2. ed. São Paulo: Expressão Popular, 2010.

BELO Monte, anúncio de uma guerra. Produção e direção: André D’Elia. Cine Delia, 2012. 1 filme (104 min), color.

BRASIL. Justiça Federal. Processo nº 0009149-40.2010.4.01.3901. Disponível em: <http://processual.trt1.jus.br/consultaprocessual/processo.php?proc=00914940201040139 01\&secao=MBA"secao=MBA $>$. Acesso em: 10 ago. 2018.

COMISSÃO Mundial de Barragens. Relatório final da fase de escopo. 1999.

DIAS, Edmundo Fernandes. Política brasileira: embate de projetos hegemônicos. São Paulo: Editora José Luis e Rosa Sundermann, 2006.

FONSÊCA, Lucas Milhomens. Movimentos sociais e redes de mobilização na Amazônia: o caso da Hidrelétrica de Belo Monte. 2018. Tese (Doutorado em Educação) - Universidade Estadual de Campinas, Campinas, 2018.

FONSÊCA, Lucas Milhomens; GOHN, Maria da Glória Marcondes. Movimentos indígenas e redes de mobilização: o caso da Usina Hidrelétrica de Belo Monte no Brasil. Eutopia, n. 12, p. $65-80$, dez. 2017.

IBGE. Cidades. 2018. Disponível em: <http://www.cidades.ibge.gov.br/painel/populacao. php/codmun=150060>. Acesso em: 28 mar. 2018.

KOHLHEPP, Gerd. Conflitos de interesse no ordenamento territorial da Amazônia brasileira. Estudos avançados, n. 16. p. 37-61, 2002.

LUKÁCS, Georg. As bases ontológicas do pensamento e da atividade do homem.

Tradução de Carlos Nelson Coutinho. Temas de Ciências Humanas, São Paulo, n. 4, p. 1-18, 1978.

MENDES, Noeli Aparecida Serafim. As usinas hidrelétricas e seus impactos: os aspectos socioambientais e econômicos do reassentamento Rural de Rosana-Euclides da Cunha Paulista. 2005. Dissertação (Mestrado em Geografia) - Universidade Estadual Paulista, Presidente Prudente, 2005.

MOURÃO, Arminda Rachel Botelho. A fábrica como espaço educativo. São Paulo: Scortecci, 2006. 
MÜLLER, Arnaldo Carlos. Hidrelétricas, meio ambiente e desenvolvimento. São Paulo: Makron Books, 1995.

OLIVEIRA, Francisco de. A reconquista da Amazônia. In: D'INCÃO, Maria Angela; SILVEIRA, Isolda Maciel da (Orgs.). A Amazônia e a crise da modernização. Belém: Museu Paraense Emílio Goeldi, 1994. v. 1, p. 85-95.

OLIVEIRA, E. Greve dos operários em Belo Monte se intensifica nos canteiros de obras e já chega ao terceiro dia. s/d. Disponível em: <http://www.cspconlutas.org.br>. Acesso em: 28 mar. 2013.

OLIVEIRA, José Alcimar de. Igara, uka, makira irúmu: epistemologia e barbárie na Amazônia em sete ensaios irredentos. 2011. Tese (Doutorado em Sociedade e Cultura da Amazônia) - Universidade Federal do Amazonas, Manaus, 2011.

OLIVEIRA, Francisco. A Reconquista da Amazônia. Novos Estudos n 38. Março de 1994.

PINTO, Lúcio Flávio. De Tucuruí a Belo Monte: a história avança mesmo? Boletim do Museu Paraense Emílio Goeldi, Ciências Humanas, v. 7, n. 3, p. 777-782, set.-dez. 2012.

PROGRAMA de comunicação indígena. UHE Belo Monte. n.2. Novembro de 2011. Disponível em: <http://restrito.norteenergiasa.com.br/site/wp-content/ uploads/2013/01/Boletim2_Plano-emergencial_Novembro2011_WEB.pdf>. Acesso em: 12 ago. 2018.

ROSA, Luiz Pinguelli et al. Estado, energia elétrica e meio ambiente: o caso das grandes barragens. COOPE/UFRJ, 1995.

SCACHETTI, Ana Ligia et al. Usina Belo Monte. 2013. Disponível em: <http://www.portalsaofrancisco.com.br>. Acesso em: 14 mar. 2013.

SILVA, Rosa Helena Dias da. Movimentos indígenas no Brasil e a questão educativa; relações de autonomia, escola e construção de cidadanias. Revista Brasileira de Educação, Caxambu. n. 13., p. 01-18, 2000.

SILVA, Elizandra Garcia. O modo de produção capitalista e o brincar de Boi-Bumbá Caprichoso e Garantido. 2015. Tese (Doutorado em Educação) - Universidade Federal do Amazonas, Parintins, 2015.

SILVA, Elizandra Garcia.; VIANA, Elma. Educação Física e a Educação Ambiental na Amazônia. In: SEMINÁRIO INTERDISCIPLINAR DE PESQUISAS EM EDUCAÇÃO E I ENCONTRO PAN-AMAZÔNICO DE EDUCAÇÃO, 12. Manus, 2018. 
SOUZA, Wanderley Lemgruber de. Impacto ambiental de hidrelátricas: uma análise comparativa de duas abordagens. 2000. Tese (Doutorado em Engenharia) - Universidade Federal do Rio de Janeiro, Rio de Janeiro, 2000.

THOMPSON, Edward Palmer. Costumes em comum. São Paulo: Companhia das Letras, 1998.

Universidade do Estado de Santa Catarina - UDESC

Centro de Ciências Humanas e da Educação - FAED

Revista PerCursos

Volume 19 - Número 40 - Ano 2018 revistapercursos@gmail.com 